\title{
The Estimation of Lipid Peroxidation and Osmotic Fragility of Human Red Blood Cell Induced by Pesticides Residues Detected in Some Vegetables Crops
}

\author{
Ali Guendouz ${ }^{1}$, Assia Belguet ${ }^{2}$, Saliha Dahamna ${ }^{3}$
}

10.18805/ajdfr.DR-232

\begin{abstract}
Background: Many studies have reported the contamination by pesticides in a variety of matrices, such as food, water and soil, which despite their use, health risk of pesticides residues on food and in drinking water for the general population has been raised. The aim of this study is to quantify the pesticides residues of Abamectin and Imidacloprid in some vegetable samples; to study the in vitro effects of the both pesticides on the lipid peroxidation and hemolytic activity and finally, based on the mathematical models we estimate the values equivalent to the concentrations of pesticide residues detected in the vegetable samples.

Methods: The extraction of pesticide residues from vegetable samples we use the FaPEx kits. Agilent Technologies 1260 infinity high performance liquid chromatography having UV/visible detector was used for the identification and quantification of pesticides residues. The results of this study proved the presence of pesticide residues in vegetable tested with higher values comparing with their corresponding MRLs.

Result: The mean of the quantity of Abamectin detected in the vegetables samples ranged from 1.93 to $4.11 \mathrm{mg} / \mathrm{kg}$ for the green pepper (Capsicum annuum spp) and courgette (Cucurbita pepo), respectively. In addition, the Imidacloprid is just detected in the cucumber (Cucumis sativus) samples and the mean value of quantity is $24.09 \mathrm{mg} / \mathrm{kg}$ and corresponding MRL is $0.05 \mathrm{mg} / \mathrm{kg}$. The in vitro study of the effects of the both pesticides on lipid peroxidation and hemolytic activity demonstrate significant effects of the different concentrations of the both pesticides on the both activities. The estimation by mathematical models of malondialdehyde quantity and hemolytic activity equivalent to the concentrations of the pesticides residues detected in vegetables samples proved the non-toxicity effects of these residues.
\end{abstract}

Key words: Abamectin, Hemolytic activity, Imidacloprid, In vitro, Lipid peroxidation, Residues.

\section{INTRODUCTION}

The high global population and improvement of living standards increase the demand for food worldwide. All sectors of the agricultural production use pesticide to prevent pests and to improve yield as well as quality of the produce, these products are subject to contamination by pesticides used to control pests and diseases. Many studies have reported the occurrence of pesticides in a variety of matrices, such as food, water, soil, meaning that both general and professional populations are often exposed to compounds from different sources; despite their use, health risk of pesticides residues on food and in drinking water for the general population has been raised (Schummer et al., 2012, Damalas and Eleftherohorinos 2011). Maximum residues limit (MRL) is presented by World Health Organization (WHO) as a criterion. This criterion expressed as pesticide concentration based on $\mathrm{mg} / \mathrm{kg}$ in fresh vegetable and fruits weight and the products which have pesticide concentration of higher than this limit are unusable (Blasco et al., 2006). Many pesticides and their residues are also known to be contributory factors in several diseases such as cancer, heart diseases, Alzeheimer's and Parkinsonism (Khaniki 2007). They are known to disturb the biochemical and physiological functions of erythrocytes thereby affecting membrane integrity and inducing the production of reactive oxygen
${ }^{1}$ National Agronomic Research Institute of Algeria, Setif Research Unit, Algeria.

${ }^{2}$ Department of Biology and Vegetal Ecology, Faculty of Sciences of Life and Nature, Setif University, Algeria.

${ }^{3}$ Department of Animal Biology and Physiology, Faculty of Sciences of Life and Nature, Setif University, Algeria.

Corresponding Author: Ali Guendouz, National Agronomic Research Institute of Algeria, Setif Research Unit, Algeria. Email: guendouz.ali@gmail.com

How to cite this article: Guendouz, A., Belguet, A. and Dahamna, S. (2022). The Estimation of Lipid Peroxidation and Osmotic Fragility of Human Red Blood Cell Induced by Pesticides Residues Detected in Some Vegetables Crops. Asian Journal of Dairy and Food Research. DOI: 10.18805/ajdfr.DR-232.

Submitted: 02-03-2021 Accepted: 05-01-2022 Online: 22-02-2022

species (ROS) and oxidative tissue damage (Mansour and Mossa 2009). Erythrocytes are particularly sensitive to oxidative damage due to the presence of high polyunsaturated fatty acid content in their membranes and high cellular concentrations of oxygen that make them a convenient cellular model suitable for studies of the toxicity of pesticides (Balaji et al., 2014). Pesticide chemicals induce oxidative stress, leading to generation of free radicals 
(Abdollahi et al., 2004) that can cause cellular damage by reacting with polyunsaturated fatty acids in cellular membranes, nucleotides in DNA and critical sulfhydryl bonds in proteins. A major form of cellular oxidation damage is lipid peroxidation, which is initiated by hydroxyl free radical through the extraction of hydrogen atom from unsaturated fatty acids of membrane phospholipids (Farber et al., 1990). In addition, many studies proved that the toxic effects of pesticides on human we can quantified by the estimation of the free radical mechanism, which can be confirmed by the direct measurement of lipid peroxidation by products such as malondialdehyde (MDA) (Feng et al., 1997). Several liquid chromatographic methods have been reported for the determination of abamectin and Imidacloprid in various crops. In addition, HPLC-UV is one of the most popular, efficient and cost effective methods of detection for microanalysis and separation of pesticides in different environmental matrices. Therefore, the present research had the following objectives: to determine the pesticide residues of Abamectin and Imidacloprid in some vegetables growing under greenhouse conditions, to determine the effect of current using pesticides on oxidative stress to establish lipid peroxidation and finally to determine the in vitro effect of Abamectin and Imidacloprid on oxidative stress biomarkers in human erythrocytes (Hemolytic activity).

\section{MATERIALS AND METHODS}

\section{Pesticides tested}

Imidacloprid is an extensively used insecticide for crop protection in the world wide due to its low soil persistence and high insecticidal activity at low application rate. It's a neurotoxic insecticide, which belongs to the class of the neonicotinoid pesticides (Daraghmeh et al., 2007), has the molecular formula of $\mathrm{C}_{9} \mathrm{H}_{10} \mathrm{CIN}_{5} \mathrm{O}_{2}$. Abamectin is a natural insecticide with stomach action and contact. It has been produced by fermentation of Streptomyces avermitilis. The commercial product of abamectin contains two active compounds $\geq 80 \%$ Avermectin B1a and $\leq 20 \%$ Avermectin $\mathrm{B} 1 \mathrm{~b}$, is a neurotoxin with the specific mechanism of action. It is effected in the nervous system by blocking the ion tropic $\alpha$-amino butyric acid (GABA) (Kolar et al., 2008).

\section{Sample pre-preparation}

The different vegetables used during this study are Green Pepper, Courgette and Cucumber. All samples of vegetables used are cut up and freeze pieces and blended to homogenize. Ensure that it is thoroughly blended and do not allow the sample to overheat during the homogenization process. The aliquots of well blended samples were kept frozen $\left(-20^{\circ} \mathrm{C}\right)$ until analysis. The frozen vegetable aliquot samples were thawed and left at room temperature $\left(25^{\circ} \mathrm{C}\right)$ before analysis (Belguet et al., 2020).

\section{Pesticides extraction and HPLC systems}

The pesticide residue analyses were conducted in the Laboratory of physical and chemical analysis of the biotechnology research center (CRBt), Constantine, Algeria, during the cropping season 2018. The FaPEx kits (Fast Pesticide Extraction) for pesticide residues extraction of vegetables samples were used; a homogenized sample of $2 \mathrm{~g}$, accurately weighed placed in a centrifuge tube and 10 $\mathrm{mL}(\mathrm{V})$ of $1 \%$ acetic acid in acetonitrile solution was added to it. After $30 \mathrm{sec}$ of oscillation by vortex, $5 \mathrm{~mL}$ of extract was transferred by micropipette into the connected syringe of the Fast Pesticide Extraction Kit (Chuang et al., 2019). To determine the pesticides residues in the vegetables samples the Analytical Technologies Agilent 1200 series HPLC having UV/visible detector was used; separation was performed on C18 $(4.6 \times 250 \mathrm{~mm})$ column. Detector was connected to the computer for data processing. The working mobile phase was Acetonitrile: Water (70:30), flow rate was $0.8 \mathrm{ml} / \mathrm{min}$, injection volume $20 \mu \mathrm{l}$, pressure 6-7 MPa. The wavelength of the detector was fixed at 210 and $270 \mathrm{~nm}$ as the preferred detection wavelength of Abamectinand Imidacloprid, respectively.

\section{Lipid peroxidation assay (LPO)}

A modified Thiobarbituricacid-reactive species (TBARS) assay (Ohkawa et al., 1979) was used to measure the lipid peroxide formed, using egg-yolk homogenates aslipid-rich media. Malondialdehyde (MDA), a secondary product of the oxidation of polyunsaturated fatty acids, reacts with two molecules of Thiobarbituric acid (TBA), yielding a pinkish red chromogen with an absorbance maximum at $532 \mathrm{~nm}$ (Janero, 1990). Egg homogenate $(250 \mu \mathrm{L}, 10 \%$ in distilledwater, v/v) and $50 \mu \mathrm{L}$ of different concentrations (10, $50,100,200,250,300$ and $400 \mu \mathrm{g} / \mathrm{ml}$ ) of pesticides tested were mixed in a test tubea nd the volume was made up to $500 \mu \mathrm{L}$, by adding distilled water and incubated for $30 \mathrm{~min}$, to induce lipid peroxidation. In addition, $\mathrm{FeSO}_{4}(0.07 \mathrm{M})$ is used as positive lipid peroxidation control. Thereafter, 750 $\mu \mathrm{L}$ of $20 \%$ acetic acid $(\mathrm{pH} 3.5)$ and $750 \mu \mathrm{L}$ of $0.8 \%$ TBA $(\mathrm{w} / \mathrm{v})$ (prepared in $1.1 \%$ sodiumdodecyl sulphate) and $25 \mu \mathrm{L} 20 \%$ TCA were added, vortexed and then heated in a boiling water bath for $60 \mathrm{~min}$. After cooling, $3.0 \mathrm{~mL}$ of 1-butanol was added to each tube and centrifuged at $3000 \mathrm{rpm}$ for 10 min. The absorbance of the organic upper layer was measured against $3 \mathrm{~mL} 1$-butanol at $532 \mathrm{~nm}$ and $600 \mathrm{~nm}$. The malondialdehyde (MDA) content in the samples was calculated from the extinction coefficient of $155 \mathrm{mM}^{-1} \mathrm{~cm}^{-1}$ for MDA-TBA abduct.

$$
\operatorname{MDA}(\mathrm{mM})=\left(\mathrm{A}_{532}-\mathrm{A}_{600}\right) / 155
$$

\section{Hemolytic activity (HA)}

About $5 \mathrm{~mL}$ of blood from healthy volunteers was collected in a tube containing heparin. The blood was centrifuged at $1500 \mathrm{rpm}$ for $3 \mathrm{~min}$. The supernatant was collected and plasma was discarded. The pellet was washed for 3 times using phosphate buffer saline (PBS) solution and centrifuged at $1500 \mathrm{rpm}$ for $5 \mathrm{~min}$. The cells were resuspended in PBS to $10 \%$. To $1 \mathrm{~mL}$ of cell suspension, $1 \mathrm{~mL}$ of different concentrations of pesticides tested $(10,50,100,200,250$, 300 and $400 \mu \mathrm{g} / \mathrm{ml})$ in phosphate buffer saline $(\mathrm{pH} 7.2)$ was 
The Estimation of Lipid Peroxidation and Osmotic Fragility of Human Red Blood Cell Induced by Pesticides Residues Detected...

added. The mixture was incubated at $37^{\circ} \mathrm{C}$ for $30 \mathrm{~min}$ and centrifuged at $2500 \mathrm{rpm}$ for $10 \mathrm{~min}$. The free hemoglobin in the supernatant was measured using spectrophotometer at $540 \mathrm{~nm}$. The phosphate buffer saline and distilled water were used as negative and positive hemolytic controls.

$\%$ hemolytic activity was calculated using the given formula:

$$
H A(\%)=\left(A_{t}-A_{n}\right) /\left(A_{c}-A_{n}\right)
$$

At- Absorbance of test sample.

An- Absorbance of control (saline).

Ac- Absorbance of control (water).

The cited above analysis are done in the laboratory of the national institute of agricultural research, unit of setif, Algeria.

\section{RESULTS AND DISCUSSION}

\section{Quantification of pesticide residues in the vegetable} samples

\section{Abamectin}

Abamectin Standard was injected in to the HPLC-UV using the conditions described in the previous section (Section: 2.3), the retention time is found as follows: $25.6 \mathrm{~min}$. To determine the concentration of the pesticide in the vegetables samples, a calibration curve was made by analysing the various solutions of pesticide (with different concentrations). The pesticide residues present in the Green pepper and Courgette samples were identified and quantified with reference to standard pesticide. The calculation of the amount of the pesticide present was carried out by comparing the peak area for unknown samples with the corresponding peak for standard, according to established procedure. All of the extracted samples were injected $(20 \mu \mathrm{L})$ separately into the HPLC-UV and peak area of the pesticide (if detected) was recorded. To calculate the pesticide residues in the vegetables samples we use directly the linearity equation:
Peak area $=77.37 \times[C] \Rightarrow[C \mathrm{mg} / \mathrm{L}]=$ Peak area/77.37

The real samples analysis indicated contamination with Abamectin pesticide with different concentration values. As shown in Table 1, the concentration of pesticide residues varied from 1.64 to $0.77 \mu \mathrm{g} / \mathrm{mL}$ for Courgette and Green pepper, respectively. Pesticide residues of the present study were compared with the maximum residue level (MRL) (Table 1) established by FAO (2016), it was found that the detected pesticide (Abamectin) was at higher levels than their corresponding MRLs value in both vegetables samples.

\section{Imidacloprid}

The Imidacloprid was characterized according to the UV, retention time and comparison with the authentic standard. The identified Imidacloprid in samples was quantified by comparison of the area of its peak recorded at $270 \mathrm{~nm}$ with calibration curves obtained from the commercial standard of the compound. In addition, the retention time of the standard Imidacloprid is $3.44 \mathrm{~min}$. Standard's calibration curve of Imidacloprid was constructed by plotting analyte concentrations against peak areas.

The standard curve equation was:

$$
\mathrm{Y}=6.177[\mathrm{X}]+3.314
$$

Where $Y$ is the peak area and $X$ is the concentration $(\mu \mathrm{g} / \mathrm{mL})$ of the pesticide standard.

The concentrations of Imidacloprid residual in cucumber samples was calculated based on the standard curve equation. The mean retention time of all samples is 3.437 with a low value of the standard deviation of 0.0005 . As shown in Table 1, the concentration of Imidacloprid residual in cucumber varied from 9.41-9.78 $\mu \mathrm{g} / \mathrm{mL}$, with a standard deviation equal to 0.20 . It was found that the detected pesticide (Imidacloprid) was at higher levels than their corresponding MRLs value in cucumber samples. Previous research suggests that the Imidacloprid can cause oxidative

\begin{tabular}{|c|c|c|c|c|c|c|}
\hline Vegetables & Samples & $\begin{array}{c}\text { Area } \\
\left(\mathrm{mAU}{ }^{*} \mathrm{~S}\right)\end{array}$ & $\begin{array}{l}\text { Retention } \\
\text { time (min) }\end{array}$ & $\begin{array}{l}\text { Concentration } \\
(\mu \mathrm{g} / \mathrm{ml})\end{array}$ & $\begin{array}{l}\text { Quantity of pesticide } \\
\text { residual }(\mathrm{mg} / \mathrm{kg})\end{array}$ & $\begin{array}{c}\mathrm{RML}^{*} \\
(\mathrm{mg} / \mathrm{kg})\end{array}$ \\
\hline \multicolumn{7}{|l|}{ Abamectin } \\
\hline \multirow[t]{2}{*}{ Courgette } & 1 & 127.233 & 25.700 & 1.644 & 4.110 & 0.02 \\
\hline & 2 & 127.058 & 25.751 & 1.642 & 4.105 & \\
\hline Mean & & 127.1455 & 25.726 & 1.64 & 4.11 & I \\
\hline Standard deviation & & 0.12 & 0.04 & 0.001 & 0.004 & I \\
\hline \multirow[t]{2}{*}{ Green pepper } & 1 & 55.258 & 25.780 & 0.714 & 1.785 & 0.02 \\
\hline & 2 & 64.229 & 25.653 & 0.830 & 2.075 & \\
\hline Mean & & 59.74 & 25.72 & 0.77 & 1.93 & I \\
\hline Standard deviation & & 6.34 & 0.09 & 0.082 & 0.205 & I \\
\hline \multicolumn{7}{|l|}{ Imidacloprid } \\
\hline \multirow[t]{3}{*}{ Cucumber } & 1 & 9,35 & 3,438 & 9,78 & 24,45 & 0.05 \\
\hline & 2 & 9,12 & 3,437 & 9,41 & 23,525 & \\
\hline & 3 & 9,31 & 3,437 & 9,72 & 24,3 & \\
\hline Mean & & 9,26 & 3,437 & 9,64 & 24,09 & I \\
\hline Standard deviation & & 0,12 & 0,00058 & 0,2 & 0,496 & I \\
\hline
\end{tabular}

Table 1: Concentration of Abamectin and Imidacloprid pesticide residues detected in vegetables samples.

RML: Maximum residue limits, *: FAO (2016). 
stress and inflammation in organs like liver and brain in rats (Duzguner and Erdogan 2010).

\section{Lipid peroxidation assay (LPO)}

The results illustrated in the Table 2 of the analysis of variance showed that the different concentrations of the two pesticides tested had a very significant effect on the occurrence of lipid peroxidation, which was estimated based on the measurement of the concentration of malondialdehyde (MDA). The MDA quantities resulting from the lipid peroxidation process under the effect of different concentrations of the pesticide Abamectin ranged between 0.0623 and $1.1827 \mu \mathrm{mol} / \mathrm{ml}$ for the concentrations 10 and $400 \mu \mathrm{g} / \mathrm{ml}$, respectively. The quantity of MDA registered at the concentration $400 \mu \mathrm{g} / \mathrm{ml}$ of the Abamectin it was bigger than the quantity of MDA in the positive control $\left(\mathrm{FeSO}_{4}\right.$, $0.07 \mathrm{M}$ ) (Table 2), these results suggest that the effect of this pesticide its very toxic under the highest concentration ( $\geq 300 \mu \mathrm{g} / \mathrm{ml}$ ). In addition, the quantity of MDA registered under the effect of different concentrations of Imidacloprid is ranged from 0.0688 to $0.7698 \mu \mathrm{mol} / \mathrm{ml}$ for the concentration 10 and $400 \mu \mathrm{g} / \mathrm{ml}$, respectively. The ANOVA analysis showed a significant difference between the quantity of MDA under the effect of $400 \mu \mathrm{g} / \mathrm{ml}$ of Imidacloprid and the positive control $\left(\mathrm{FeSO}_{4}, 0.07 \mathrm{M}\right)$. The highest value of MDA is registered by the positive control $\left(\mathrm{FeSO}_{4}, 0.07 \mathrm{M}\right)$ (Table 2). Therefore, lipid peroxidation has been suggested as one of the molecular mechanisms involved in pesticideinduced toxicity (Banarjee et al., 1999). Lipid peroxidation which is the major contributor to the loss of cell function, enzyme inactivation and hormone oxidation are indicators of oxidative cell damage (Ruas et al., 2008). In addition to their principal mode of action, lambda cyhalothrin, chlorpyrifos and imidacloprid have been reported to cause oxidative stress and lipid peroxidation both in vitro and in vivo (Abdallah et al., 2012, Fetoui et al., 2008). El-Shenawy (2010) who studied the toxic effect of Abamectin on isolated rat hepatocytes found that Abamectin induced significant increase in lipid peroxidation activities and decrease the cell viability.

\section{Hemolytic activity (HA)}

As shown in Table 3, the analysis of variance showed that the different concentrations of the two pesticides tested had a very significant effect on the hemolytic activity (osmotic fragility OF). Based on the study of Amin and Dannenfelser (2006), the $10 \%$ and $25 \%$ hemolysis are the relative boundaries, in other words any hemolysis value below $10 \%$ is considered to be non-hemolytic while values above $25 \%$ hemolysis were assumed as toxic. The pesticides tested in the present study caused increased osmotic fragility of erythrocytes at the different concentrations. The results of hemolysis at the concentrations of the both pesticides tested ranged from 10 to $200 \mu \mathrm{g} / \mathrm{ml}$ were assumed as nonhemolytic, but the percentages of hemolysis registered under the high concentrations of the two pesticides tested
400 and $500 \mu \mathrm{g} / \mathrm{ml}$ were considered as hemolytic (Table 3). This type of hemolytic activity may be due to the lysis of the cell or some disturbances in the membrane integrity of RBCs and may be due to the reduced xenobiotic compounds, such as phenols, that are capable of promoting hemolysis through oxidation of hemoglobin, forming metahemoglobin (Bukowska and Kowalska, 2004). Singh et al., (2004) studied 4 organophosphate pesticides (Dimethoate, Chlorpyrifos, Ethion and Monocrophos) on porcine erythrocytes and found that the 4 pesticides increased hemolysis and potassium leakage from erythrocytes.

\section{Estimation of LPO and HA (\%) induced by the Pesticide residues detected}

To estimate the quantity of malondialdehyde (MDA) and the percentage of hemolytic activity (HA) which equivalent to the concentration of pesticide residues detected in the vegetable samples, we use the equation of the relationships

Table 2: Lipid peroxidation induced by pesticides tested.

\begin{tabular}{|c|c|c|}
\hline \multirow{2}{*}{$\begin{array}{l}\text { Pesticides } \\
\text { concentrations } \\
(\mu \mathrm{g} / \mathrm{ml})\end{array}$} & \multicolumn{2}{|c|}{$\begin{array}{l}\text { Malondialdehyde concentration (MDA) } \\
(\mu \mathrm{mol} / \mathrm{ml})\end{array}$} \\
\hline & Abamectin & Imidacloprid \\
\hline 10 & $0.0623 \pm 0.0037$ (d) & $0.0838 \pm 0.0170(\mathrm{e})$ \\
\hline 50 & $0.0774 \pm 0.0170(\mathrm{~d})$ & $0.0688 \pm 0.0260$ \\
\hline 100 & $0.0795 \pm 0.0134(d)$ & $0.3333 \pm 0.0268(d)$ \\
\hline 200 & $0.5655 \pm 0.0260(\mathrm{c})$ & $0.4559 \pm 0.0388$ (c) \\
\hline 250 & $0.6602 \pm 0.0409(c)$ & $0.5053 \pm 0.0599$ (c) \\
\hline 300 & $0.9763 \pm 0.0037(b)$ & $0.7376 \pm 0.0378(\mathrm{~b})$ \\
\hline 400 & $1.1827 \pm 0.2668(a)$ & $0.7698 \pm 0.0318(b)$ \\
\hline $\mathrm{FeSO}_{4}(0.07 \mathrm{M})$ & $0.8602 \pm 0.0366(b)$ & $0.8602 \pm 0.0368$ \\
\hline Concentration effect & $* * *$ & $* * *$ \\
\hline Mean & 0.558 & 0.4768 \\
\hline Min & 0.0623 & 0.0838 \\
\hline Max & 1.1827 & 0.8602 \\
\hline LSD $5 \%$ & 0.168 & 0.0629 \\
\hline
\end{tabular}

Min: Minimum, Max: Maximum and LSD: Least significant difference.

Table 3: The hemolytic activity of pesticides tested.

\begin{tabular}{|c|c|c|}
\hline \multirow{2}{*}{$\begin{array}{l}\text { Pesticides } \\
\text { concentration } \\
(\mu \mathrm{g} / \mathrm{ml})\end{array}$} & \multicolumn{2}{|c|}{$\begin{array}{l}\text { The percentages of hemolytic activity } \\
\qquad(\%)\end{array}$} \\
\hline & Abamectin & Imidacloprid \\
\hline 10 & $2,79 \pm 0,24$ (c) & $2,92 \pm 0,04$ (c) \\
\hline 25 & $3,01 \pm 0,06$ (c) & $3,23 \pm 0,12$ (c) \\
\hline 50 & $4,13 \pm 0,68$ (c) & $3,52 \pm 0,28$ (c) \\
\hline 100 & $5,06 \pm 0,22$ (c) & $0,04 \pm 3,95$ (c) \\
\hline 200 & $5,81 \pm 0,19$ (c) & $4,51 \pm 0,05$ (c) \\
\hline 400 & $55,82 \pm 5,83$ (b) & $51,73 \pm 2,32(b)$ \\
\hline 500 & $100 \pm 0,18$ (a) & $100 \pm 0,04$ (a) \\
\hline $\begin{array}{l}\text { Concentration } \\
\text { effect }\end{array}$ & $* * *$ & $* * *$ \\
\hline LSD 5\% & 6,75 & 2,69 \\
\hline
\end{tabular}

LSD: Least significant difference. 
between the variation of the different concentrations of the both pesticides tested and the variation of MDA and HA\%, Fig 1 and Fig 2, respectively.

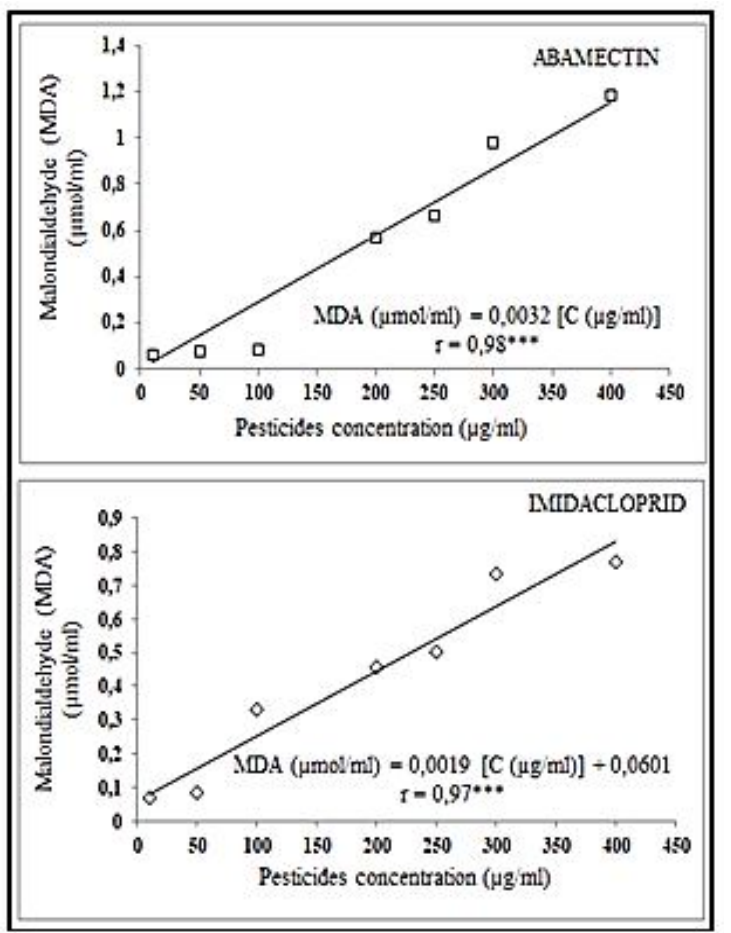

Fig 1: The relationship between the different concentrations of the pesticides tested and the Malondialdehyde values.

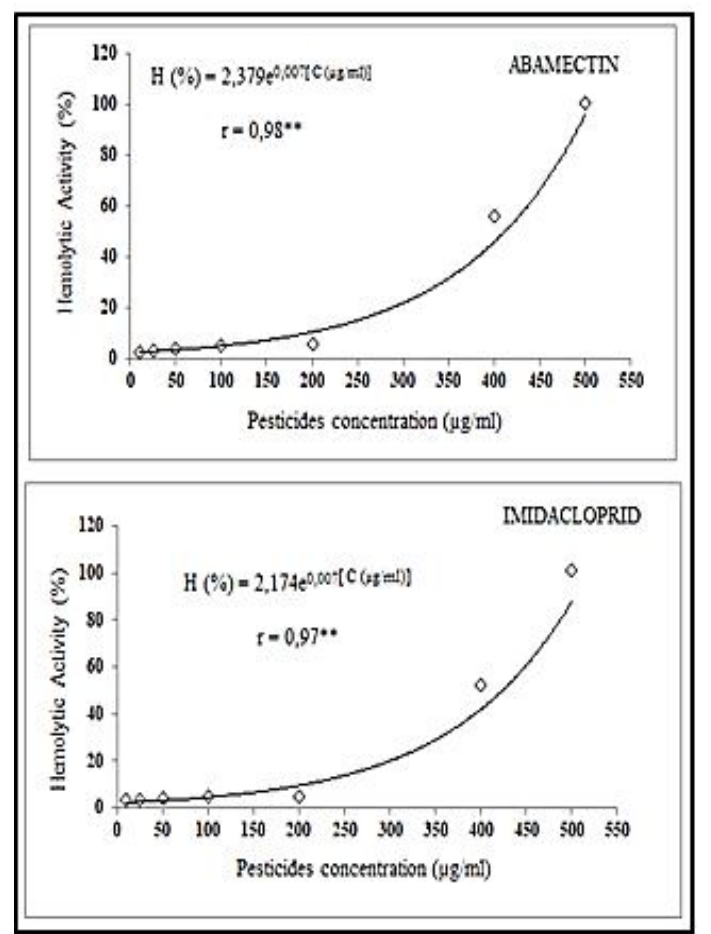

Fig 2: The relationship between the different concentrations of the pesticides tested and the hemolytic activity values.

\section{Estimation of lipid peroxidation (LPO)}

As shown in the Fig 1 , there is a significant and positive correlation between the different concentrations of the both pesticides Abamectin and Imidacloprid and the concentration of MDA $\left(r=0.98^{* * *}\right.$ and $r=0.97^{* * *}$, respectively). The estimated malondialdehyde quantities at the equivalent concentrations of the both pesticides residues detected in vegetable samples are illustrated in Table 4. The values of estimated quantities of MDA which equivalent to the Abamectin pesticide residues for the Green pepper, Cucumber and Courgette are 0.0024, 0.0044 and 0.0052 $\mu \mathrm{mol} / \mathrm{ml}$, respectively; the comparison between these results and the values registered under the effect of the positive control $\left(\mathrm{FeSO}_{4}, 0.8602 \mu \mathrm{mol} / \mathrm{ml}\right)$, demonstrate that the effect of the Abamectin pesticide residues detected on the lipid peroxidation is very weak. In addition, the Imidacloprid pesticide residues are registered just in the Cucumber, the estimated malondialdehyde quantity at the equivalent concentration is $0.0784 \mu \mathrm{mol} / \mathrm{ml}$; the comparison of the last one value with the quantity of MDA registered under the effect of the positive control $\left(\mathrm{FeSO}_{4}, 0.8602 \mu \mathrm{mol} / \mathrm{ml}\right)$, proved that the Imidacloprid pesticide residues registered in the Cucumber had a weak effect on the lipid peroxidation measured by the quantification of malondialdehyde. Dysregulation in oxidative stress and lipid peroxidation biomarkers in rats exposed to Imidacloprid was reported (Mohany et al., 2011, Kapoor et al., 2010).

\section{Estimation of hemolytic activity (HA\%)}

Based on the results illustrated in the Fig 2, the percentage of Hemolytic Activity (HA\%) correlated positively and significantly ( $r=0.98^{* *}$-Abamectin- and $r=0.97^{* *}$-Imidacloprid-) with the different concentrations of the both pesticides tested. The exponential equations registered between the variations of the $\mathrm{HA} \%$ and the Abamectin and Imidacloprid concentrations allow to estimate the percentage of Hemolytic Activity equivalent to the concentrations of pesticide residues detected in vegetable samples. As shown in the Table 4 , the values of estimated $\mathrm{HA} \%$ equivalent to the concentrations of Abamectin pesticide residues detected in the cucumber, green pepper and courgette are 2.37, 2.39 and $2.40 \%$, respectively. Amin and Dannenfelser (2006) suggested that any hemolysis value below $10 \%$ is considered to be non-hemolytic; these results confirme the nontoxicity of the Abamectin pesticide residues detected in vegetable samples. The value of estimated $\mathrm{HA} \%$ equivalent to the concentration of Imidacloprid pesticide residues registered in cucumber is $2.17 \%$, this value is less than the relative boundaries suggested by Amin and Dannenfelser (2006) (10\%). Over all, many studies proved that the erythrocyte osmotic fragility (EOF) or hemolytic activity, is very suitable analysis as an indirect method of assessing oxidative stress (Chihuailaf et al., 2002) and toxicity of pesticides (Narendra et al., 2007), as it gives information about the total status of red cell metabolism and membrane stability. In addition, the increased erythrocyte osmotic fragility observed indicates the ability of the pesticides to compromise the integrity of the erythrocyte membrane 
The Estimation of Lipid Peroxidation and Osmotic Fragility of Human Red Blood Cell Induced by Pesticides Residues Detected...

Table 4: The estimation of Malondialdehyde concentrations and Hemolytic Activity induced by the Pesticide residues detected in vegatable samples.

\begin{tabular}{|c|c|c|c|c|}
\hline \multirow{2}{*}{$\begin{array}{l}\text { Pesticides } \\
\text { Vegetables }\end{array}$} & \multicolumn{2}{|c|}{ Abamectin } & \multicolumn{2}{|c|}{ Imidacloprid } \\
\hline & $\begin{array}{c}\text { Pesticide residues } \\
\text { concentration } \\
(\mu \mathrm{g} / \mathrm{ml})\end{array}$ & $\begin{array}{l}\text { Estimated MDA } \\
\text { concentration } \\
(\mu \mathrm{mol} / \mathrm{ml})\end{array}$ & $\begin{array}{c}\text { Pesticide residues } \\
\text { concentration } \\
(\mu \mathrm{g} / \mathrm{ml})\end{array}$ & $\begin{array}{c}\text { Estimated MDA } \\
\text { concentration } \\
(\mu \mathrm{mol} / \mathrm{ml})\end{array}$ \\
\hline Cucumber & 1,4 & 0,0044 & 9,64 & 0,0784 \\
\hline Courgette & 1,64 & 0,0052 & ND & ND \\
\hline Green pepper & 0,77 & 0,0024 & ND & ND \\
\hline Vegetables & $\begin{array}{c}\text { Pesticide residues } \\
\text { concentration } \\
(\mu \mathrm{g} / \mathrm{ml})\end{array}$ & $\begin{array}{c}\text { Estimated } \\
\text { hemolytic activity } \\
(\%)\end{array}$ & $\begin{array}{c}\text { Pesticide residues } \\
\text { concentration } \\
(\mu \mathrm{g} / \mathrm{ml})\end{array}$ & $\begin{array}{c}\text { Estimated } \\
\text { hemolytic activity } \\
(\%)\end{array}$ \\
\hline Cucumber & 1,40 & 2,37 & 9,64 & 2,17 \\
\hline Courgette & 1,64 & 2,40 & ND & ND \\
\hline Green pepper & 0,77 & 2,39 & ND & ND \\
\hline
\end{tabular}

apparently from increased oxidative damage to the erythrocyte membrane, which may result in anemia, many studies proved intoxication for some workers by pesticides in form of anemia (Uchendu et al., 2014).

\section{CONCLUSION}

The residues of Abamectin and Imidacloprid in the tested vegetables are higher then the RMLs values, there is a significant effects of pesticides tested on the lipid peroxidation and hemolytic activity under different concentrations. The quantity of MDA registered at the highest concentration of the Abamectin it was bigger than the quantity of MDA at the positive control $\left(\mathrm{FeSO}_{4}, 0.07 \mathrm{M}\right)$, this rustles suggest that the effect of this pesticide its very toxic under the highest concentration, but in contrary under the effect of Imidacloprid the highest value of MDA registered under the effect of positive control $\left(\mathrm{FeSO}_{4}, 0.07 \mathrm{M}\right)$. Based on the study of Amin and Dannenfelser (2006), the 10\% hemolysis is the relative boundaries, in other words any hemolysis value below $10 \%$ is considered to be nonhemolytic. The results suggest that there is non-hemolytic effect at the lower concentrations of the both pesticides tested. Based on the equations of the variation between the concentrations of pesticides tested and the quantity of MDA and hemolytic activity, we estimate the quantity of MDA and hemolytic activity equivalent to the concentrations of Abamectin and Imidacloprid residues detected in vegetables samples, for the MDA quantity and in all vegetables samples the estimated values are not toxic in comparison with the positive control $\left(\mathrm{FeSO}_{4}, 0.07 \mathrm{M}\right)$. In addition, the value of hemolytic activity estimated based on the concentrations of pesticides residues detected in vegetables samples proved the non-hemolytic effects of these residues.

\section{ACKNOWLEDGEMENT}

Many thank for Mr. Davis Lee, Tony Lin and Rodney Cheng for the support and very much thankful to GETECH supporting for the FaPEx kits.

Conflict of interest: None.

\section{REFERENCES}

Abdallah, F., Fetoui, H., Fakhfakh, F. and Keskes, L. (2012). Caffeic acid and quercetin protect erythrocytes against the oxidative stress and the genotoxic effects of lambdacyhalothrin in vitro. Hum. Exp. Toxicol. 31: 92-100.

Abdollahi, M., Ranjbar, A., Shadnia, S., Nikfar, S. and Rezaie, A. (2004). Pesticide and oxidative stress: a review. Medical Science Monitor. 10(6): 141-147.

Amin, K. and Dannenfelser, R.M. (2006). In vitro hemolysis: Guidance for the pharmaceutical scientist. J. Pharm Sci. 95:1173-1176.

Balaji, B., Rajendar, B. and Ramanathan, M. (2014). Quercetin protected isolated human erythrocytes against mancozeb-induced oxidative stress. Toxicology and Industrial Health. 30(6): 561-569.

Banerjee, B.D., Seth, V., Bhattacharya, A., Pasha, S.T., Chakraborty, A.K. (1999). Biochemical effects of some pesticides on lipid peroxidation and free-radical scavengers. Toxicology Letters. 107(1-3): 33-47.

Belguet, A., Dahamna, S., Abdessemed, A., Ouffroukh, K. and Guendouz, A. (2020). Assessment of human health risk associated with the Imidacloprid pesticide. Indian Journal of Environmental Protection. 40(2): 155-160.

Blasco, C., Font, G. and Picó, Y. (2006). Evaluation of 10 pesticide residues in oranges and tangerines from Valencia (Spain). Food Control. 17(11):841-846.

Bukowska, B. and Kowalska, S. (2004). Phenol and catechol induce prehemolytic and hemolytic changes in human erythrocytes. Toxicol Lett. 152: 73-84.

Chuang, W.C., Chen, J.W., Huang, C.H., Shyu, T.H., Lin, S.K. (2019). FaPEX® Multipesticide Residues Extraction Kit for Minimizing Sample Preparation Time in Agricultural Produce. Journal of AOAC International. 102: 1-13. https://doi.org/10.5740/ jaoacint. 18-0271.

Chihuailaf, R.H., Contreras, P.A. and Wittwer, F.G. (2002). Pathogenesis of oxidative stress: consequences and evaluation in animal health. Vet. Mex. 33: 265-283.

Damalas, C.A. and Eleftherohorinos, I.G. (2011). Pesticide exposure, safety issues and risk assessment indicators. International Journal of Environmental Research and Public Health. 8: 1402-1419. 
The Estimation of Lipid Peroxidation and Osmotic Fragility of Human Red Blood Cell Induced by Pesticides Residues Detected...

Daraghmeh, A., Shraim, A., Abulhaj, S., Sansour, R. and Ng, J.C. (2007). Imidacloprid residues in fruits, vegetables and water samples from Palestine. Environmental Geochemistry Health. 29(1): 45-50.

Duzguner, V. and Erdogan, S. (2010). Acute oxidant and inflammatory effects of imidacloprid on the mammalian central nervous system and liver in rats. Pestic. Biochem. Physiol. 97: 13-18.

El-Shenawy, N.S. (2010). Effects of insecticides fenitrothion, endosulfan and abamectin on antioxidant parameters of isolated rat hepatocytes. Toxicol. In Vitro. 24: 1148-1157.

FAO (2016) Evaluation of Pesticide Residues: For Estimation of Maximum Residue Limits and Calculation of Dietary Intake, Training Manual. FAO, Rome.

Farber, J.L., Kyle, M.E. and Coleman, J.B. (1990). Biology of disease: Mechanisms of cell injury by activated oxygen species. La. Inves. 62: 670-679.

Feng, N., George Hsiao, Ko. and Yueh, H.K. (1997). Protection of oxidative hemolysis by demethyldiisoeugenol in normal and thalassemia red blood cells Free Radical Biol. Med. 22: 217.

Fetoui, H., Garoui, E.M. and Zeghal, E. (2009). Lambdacyhalothrininduced biochemical and histopathological changesin the liver of rats: Ameliorative effect of ascorbic acid. Exp. Toxicol. Pathol. 61: 189-196.

Fetoui, H., Garoui, E.M., Makni-ayadi, F. and Zeghal, N. (2008). Oxidative stress induced by lambda-cyhalothrin in rat erythrocytes and brain: attenuation by vitamin C. Environ. Toxicol.Pharmacol. 26: 225-231.

Janero, D.R. (1990). Malondialdehyde and thiobarbituric acid reactivityas diagnostic indices of lipid peroxidation and peroxidativetissue injury. Free Radical Biology and Medicine. 95(6): 515-540.

Kapoor, U., Srivastava, M.K., Bhardwaj, S. and Srivastava, L.P. (2010). Effect of imidacloprid on antioxidant enzymes and lipid peroxidation in female rats to derive it's No Observed Effect Level (NOEL). J. Toxicol. Sci. 35: 577-581.
Khaniki, G.R. (2007). Chemical contaminants in milk and public health concerns: A review. Int. J. Dairy Sci. 2: 104-115.

Kolar, L., Kojzuh Erjzen, N., Hogerwerf, L. and vanGestel, C.A.M. (2008). Toxicity of abamectin and doramectin to soil invertebrates. Environmental Pollution. 151(1): 182-189.

Mansour, S.A. and Mossa, A.H. (2009). Lipid peroxidation and oxidative stress in rat erythrocytes induced by chlorpyrifosand the protective effect of zinc. Pesticide Biochemistry and Physiology. 93: 34-39.

Mohany, M., Badr, G., Refaat, I. and El-Feki, M. (2011). Immunological and histological effects of exposure to Imidacloprid insecticide in male albino rats. Afr. J. Pharm. Pharmacol. 5: 2106-2114.

Narendra, M., Bhatracharyulu, N., Padmavathi, P. and Varadacharyulu, N. (2007). Prallethrin induced biochemical changes in erythrocyte membrane and red cell osmotic haemolysis in human volunteers, Chemospheres. 67: 1065-1071.

Ohkawa, H., Ohishi, N. and Yagi, K. (1979). Assay for lipid peroxides in animal tissues by thiobarbituric acid reaction. Analytical Biochemistry. 95(2): 351-358.

Ruas, C.B., Carvalho Cdos, S., de Araújo, H.S., Espíndola, E.L., Fernandes, M.N. (2008). Oxidative stress biomarkers of exposure in the blood of cichlid species from a metalcontaminated river. Ecotoxicol Environ Saf. 71: 86-93.

Schummer, B.C., Briand, G.S., Millet, O.M. and Appenzeller, B.M.R. (2012). Determination of farm workers' exposure to pesticides by hair analysis, Toxicol. Lett. 210 (2): 203-210.

Singh, M., Sandhir, R. and Kiran, R. (2004). In vitro effects of organophosphate pesticides on rat erythrocytes. Indian J. Exp Biol. 42:292-296.

Uchendu, C., Ambali, S.F., Ayo, J.O., Esievo, K.A.N. and Umosen, A.J. (2014). Erythrocyte osmotic fragility and lipid peroxidation following chronic co-exposure of rats to chlorpyrifos and deltamethrin and the beneficial effect of alpha-lipoic acid. Toxicology Reports. 1: 373-378. 